\title{
CABBAGE KALE - A NEW FUNCTIONAL FOOD PRODUCT: GROWING CONDITIONS AND REGULATION OF THE PHYTOCHEMICAL COMPOSITION
}

\author{
Esraa Almughraby $^{1^{*}}$ (D), Marat Ildusovich Kalimullin ${ }^{2}$ (D), Antonina Anatolyevna Mostyakova ${ }^{3}$ (D), \\ Olga Arnoldovna Timofeeva ${ }^{4}$ (iD
}

\footnotetext{
${ }^{1}$ Research Scholar, Department of Botany and Plant Physiology, Institute of Fundamental Medicine and Biology, Kazan Federal University.

${ }^{2}$ Assistant professor of the Department of Botany and Plant Physiology, Institute of Fundamental Medicine and Biology, Kazan Federal University.

${ }^{3}$ Associate professor of the Department of Botany and Plant Physiology, Institute of Fundamental Medicine and Biology, Kazan Federal University.

${ }^{4}$ Professor, the chairman of the Department of Botany and Plant Physiology, Institute of Fundamental Medicine and Biology, Kazan Federal University.
}

Received - September 25, 2020; Revision - November 10, 2020; Accepted - December 10, 2020

Available Online December 15, 2020

DOI: http://dx.doi.org/ 10.18006/2020.8(Spl-2-AABAS).S264.S271

\section{KEYWORDS \\ Cabbage Kale \\ Antioxidant Systems \\ Reactive Oxygen Species \\ Negative Temperatures \\ Growth Regulators \\ Ontogenesis}

\begin{abstract}
The purpose of this work was to evaluate the specific effects of natural growth hormones (gibberellic acid, $10^{-6} \mathrm{M}$ and brassinolide, $10^{-6} \mathrm{M}$ ) and commercial growth bio-stimulator (Novosil, $5 \mathrm{~g} / \mathrm{ha}$ ) on the enzymatic and non-enzymatic antioxidants activities of cabbage kale plants, under different growing conditions. The treatment of growth regulators was imposed by soaking cabbage kale plant seed in various growth regulators for 24 hours. The results were recorded at 85,115 and 145 days after planting, at $+8^{0} \mathrm{C}, 0^{\circ} \mathrm{C}$ and $6^{\circ} \mathrm{C}$ temperature, respectively. Among the studied growth regulators, terpenoidal compounds of Novosil and gibberellic acid improved the antioxidant activity, activating enzymatic antioxidant systems and increasing the content of carotenoids and proline in leaves of cabbage kale. The steroidal compound of brassinolide raises the content of phenolic and flavonoids compounds which increased antioxidant activities. The results obtained from the study indicated that the use of growth regulars increases the synthesis of protective compounds, which developed resistance of cabbage kale plants against adverse environmental factors and improve the biomedical properties of cabbage kale. Further, the results of the study also suggested that freezing temperatures $(-60 \mathrm{C})$ enhanced the protective effect of growth regulators against lipid peroxidation and their antioxidant activity.
\end{abstract}

* Corresponding author

E-mail: esraaalmgrabe@gmail.com_Esraa Almughraby)

Peer review under responsibility of Journal of Experimental Biology and Agricultural Sciences.

Production and Hosting by Horizon Publisher India [HPI] (http://www.horizonpublisherindia.in/).

All rights reserved.
All the articles published by Journal of Experimental Biology and Agricultural Sciences are licensed under a Creative Commons Attribution-NonCommercial 4.0 International License Based on a work at www.jebas.org.

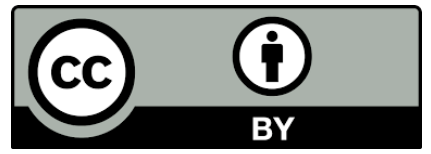




\section{Introduction}

Cabbage kale (Brassica oleracea var. Sabellica) refers to frostresistant plants. In late autumn, cabbage kale is exposed to low or even negative temperatures during its growth, and it grows at low levels of photosynthetically active radiation. This low-temperature exposure activates the processes of cold acclimation of plants, resulting in changes of various biochemical and physiological changes, which lead to increased frost resistance (Levitt, 1980). Antioxidant systems are important for the adaptation of plants to various adverse environmental factors. They can protect reactive oxygen species, forming when cells are damaged from stress. Cabbage kale has a high antioxidant activity; it contains polyphenols, flavonoids, carotenoids, glucosinolate hydrolysis products, vitamins $\mathrm{C}$ and $\mathrm{E}$, which are effective antioxidants According to Zhou \& Yu (2006), cabbage kale, spinach, broccoli, and rhubarb had the highest antioxidant activity among 38 studied species of vegetables. Similarly, Sikora et al. (2008) also revealed that cabbage kale had the highest antioxidant activity, compared to other species of cabbage, such as white cabbage, broccoli, Brussels sprouts, green kale and cauliflower.

It is widely recognized that food with high phenolic and flavonoid content having higher antioxidant activity, which can help these plants to protect themselves from free radicals and reactive oxygen species and prevent chronic diseases. However, the level of these compounds depends on environmental factors and conditions of growth. The purpose of the work was to define the specific effects of natural hormones (gibberellic acid, brassinolide) and commercial growth biostimulator (Novosil) on the content and activity of enzymatic and non-enzymatic antioxidants in cabbage kale plants, under different growing conditions of ontogenesis.

\section{Materials and Methods}

The cabbage was planted in early July 2019. Before planting, seeds were treated with various growth regulators viz., gibberellic acid $10^{-6} \mathrm{M}$, Novosil $5 \mathrm{~g} / \mathrm{ha}$, brassinolide $10^{-6} \mathrm{M}$ by soaking them for 24 hours. For analysis, leaves samples were collected at three stages of growth viz., 85 days after planting @ $+8^{0} \mathrm{C}$ temperature, 115 days after planting @ $0^{0} \mathrm{C}$ temperature, and 145 days after planting (a) $6{ }^{0} \mathrm{C}$ temperature.

Phenolic compounds were determined by using Folin- Ciocalteu method with some modification and the absorbency was measured by spectrophotometer at $725 \mathrm{~nm}$ (Velioglu et al., 1999). The content of phenolic compounds was evaluated in terms of the equivalent amount of gallic acid. Flavonoids were detected by reaction with $\mathrm{AlCl}_{3}$ by the colorimetric method at a wavelength of $420 \mathrm{~nm}$ (Zhishen et al., 1999). Vitamin C content was determined as the sum of ascorbic acid and dehydroascorbic acid, using the spectrophotometric method (Sokolovsky et al., 1974). Wettstein formula was used to define the content of carotenoids in the acetone extract (Vorobyev et al., 2013). The content of malonyldialdehyde was evaluated according to the degree of accumulation of the product and its reaction with thiobarbituric acid (Kumar \& Knowles, 1993). The content of proline in leaves and roots of plants was determined using the Bates method (Bates et al., 1973). While, peroxidase activity was identified by the Boyarkin method; ascorbate peroxidase activity was evaluated by the Verma and Dubei method, and catalase activity was defined by the Ebi method (Sibgatullina et al., 2011).

The experiments were carried out in three replicates and the statistical data were processed using Microsoft Excel. The reliability of difference was determined by the Mann-Whitney test at $\mathrm{P} \leq 0.05$.

\section{Results and Discussion}

The reactions of lipid peroxidation constantly occur in the organism. Free radical oxidation disrupts the structure of many molecules. Amino acids are oxidized in proteins; as a result of this protein structure is destroyed. These activate proteolytic enzymes in the cell, which hydrolyze and damaged proteins. Along with this, these reactive oxygen species (ROS) easily disrupt the structure of DNA. Fatty acids, containing double bonds and located through $\mathrm{CH}_{2}$ group, are the most susceptible to the action of reactive oxygen species. Plants have enzymatic and nonenzymatic systems of antioxidant defense, which help to eliminate or to reduce ROS toxicity. These systems correlate with plant tolerance to abiotic stress (Mittler, 2002).

The degree of oxidative stress in cells is assessed by the intensity of lipid peroxidation. In the current study, level of lipid peroxidation in cabbage kale plants is determined by the accumulation of malondialdehyde, which is the indicator of membrane system disruption.

Results given in figure 1 revealed that lipid oxidation of plasma membrane increases at low temperatures in the control group that is consistent with the previous literature (Prassad, 1996). Further, the application of gibberellic acid and Novosil reduced the degree of lipid peroxidation under these conditions (Fig. 1). Thus, the growth regulators protect the membrane system from oxidation by reactive oxygen species.

The degree of plant damage from ROS depends on the balance rates of their formation and detoxification. Various antioxidants play an important role in ROS neutralization reactions. Under stress, plants often respond by the accumulation of secondary metabolites, especially flavonoids (Falcone Ferreyra et al., 2012). Flavonoids and derivatives of hydroxycinnamic acid, due to their ability to absorb ultraviolet light and part of the visible light, 


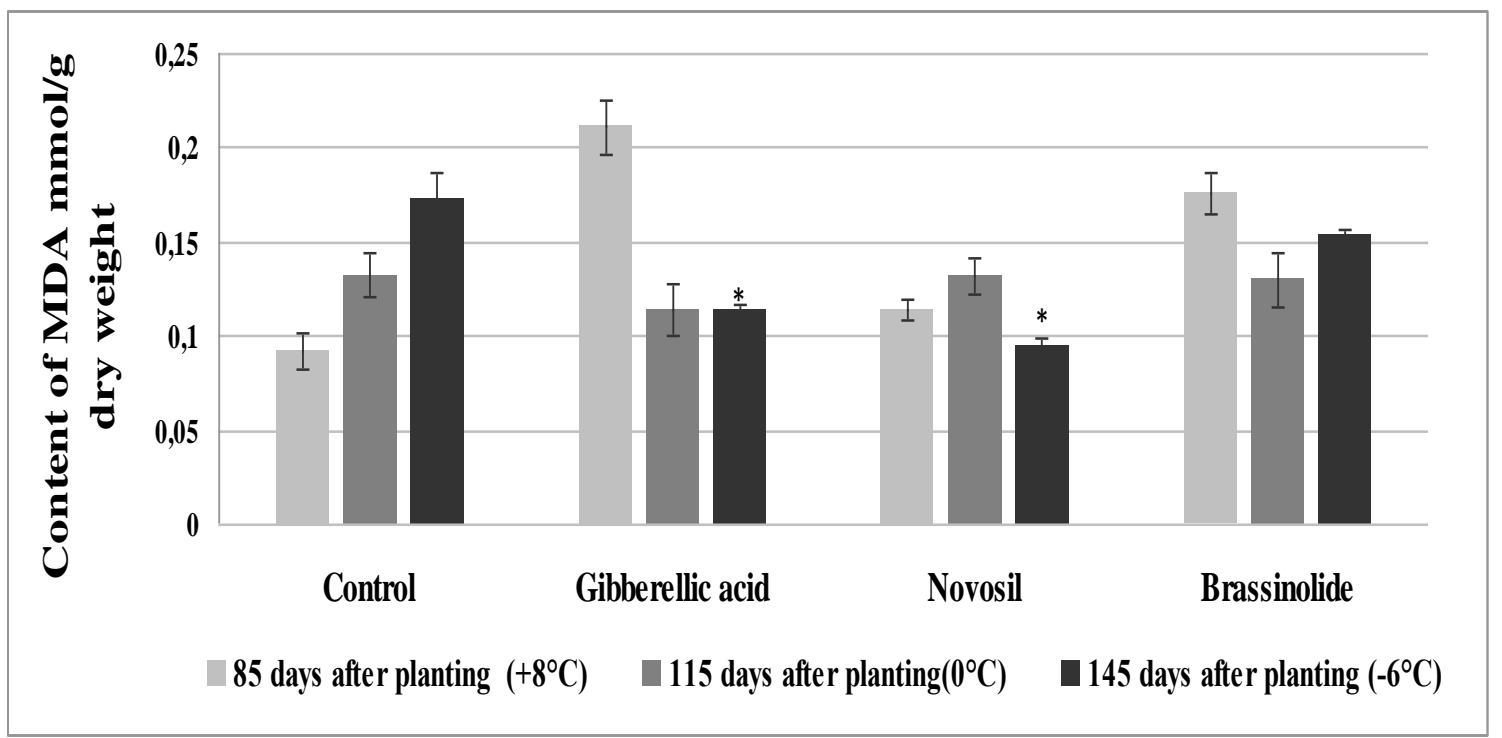

Figure 1 Effect of growth regulators on the content of malondialdehyde in Brassica oleracea var. Sabellica

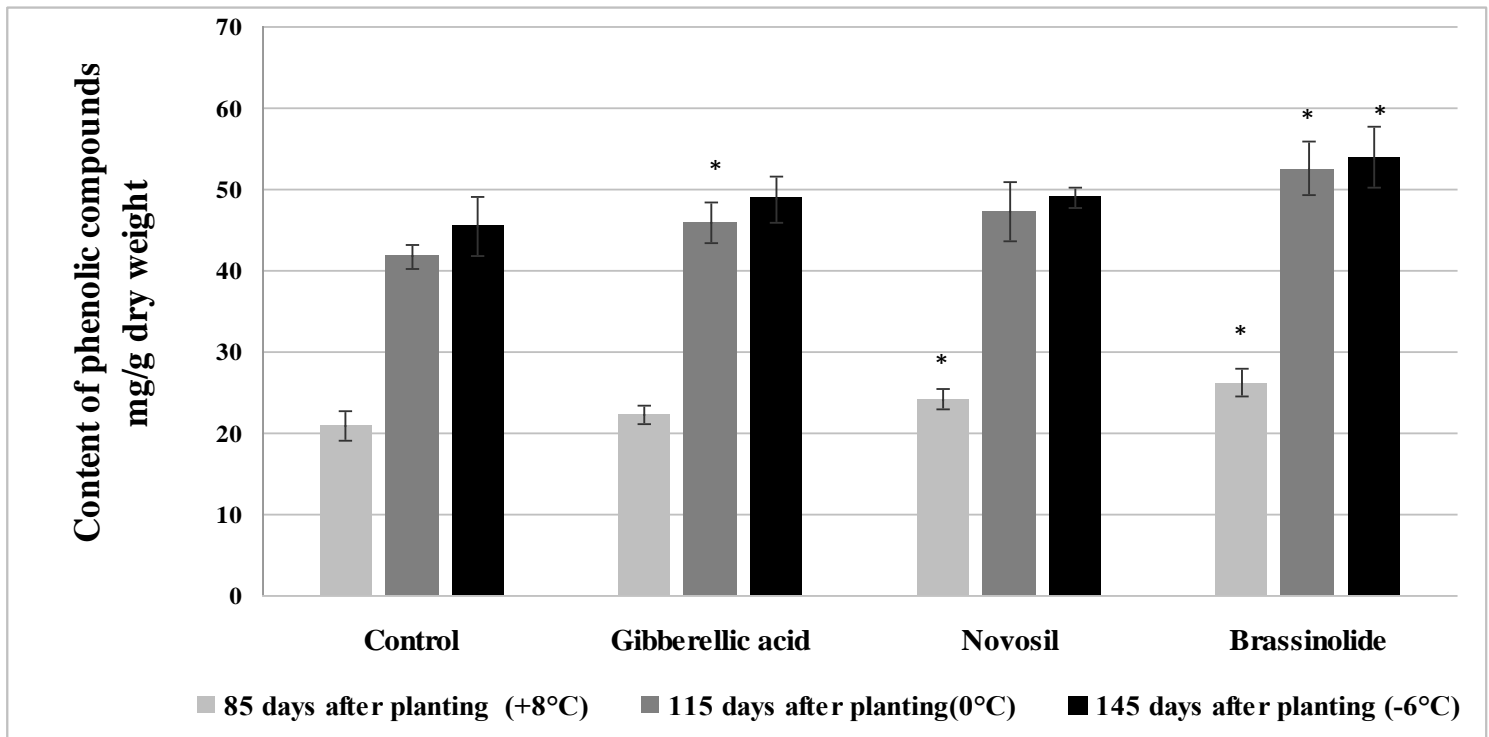

Figure 2 Effect of growth regulators on the content of phenolic compounds in Brassica oleracea var. Sabellica

protect the plants from damage, caused by the high levels of solar radiation. Besides, phenolic compounds can intercept peroxide radicals and other reactive oxygen species, and also participate in the inhibition of oxygen activating enzymes (Edreva, 2005). Compared to other leafy vegetables, cabbage kale leaves have a high concentration of natural glycosides of flavonoid and hydroxycinnamic acid derivatives (Fiol et al., 2012).

In the current study, the content of phenolic compounds increased at various intermediate growth stages of cabbage kale leaves (from 85 to 145 days after planting). These data were consistent with the results obtained by Pandjaitan et al. (2005), who investigated the changes in the content of phenolic compounds in spinach leaves at different stages of maturity (juvenile, middle-mature and fullyripened). Further, these researchers reported that phenolic and flavonoids compounds were higher at the middle maturity phase as compared to the full maturity and juvenile leaves. This increase is, probably, due to the most active plant metabolism, which accompanies rapid growth during the first few months (Figure 2).

Besides this increase in the level of phenolic compounds may be associated with the decrease in temperature. It was shown that the 
low temperature intensified the synthesis of phenolic and flavonoids compounds, due to the increase in the amount of ROS (Moheb et al., 2011).

Among the studied growth regulators, the only brassinolide has raised the content of phenolic compounds at all stages of plant growth. Further, it was noticed that its effect was significantly enhanced under the conditions of negative (low) temperatures (Figure 2). It was shown that brassinosteroids were involved in the regulation of plant development and adaptation to stress factors (Efimova et al., 2017). It can be assumed that under temperature stress conditions, the antioxidant effect of brassinolide on cabbage kale plants is implemented through the accumulation of low molecular weight phenolic compounds.

The results of the study revealed that the content of flavonoids in control plants does not depend on the age of plants and various climatic conditions (Figure 3). These results were consistent with the findings of Schmidt et al. (2010), who suggested that the number of flavonoids remained unchanged with decreasing temperature and radiation in six out of eight varieties of cabbage kale (Schmidt et al., 2010).

In current experiments, all studied growth regulators increase the number of flavonoids. Among the studied growth regulators, brassinolide had the highest effect on the content of flavonoids, and its effect was significantly enhanced at lower temperatures (Figures 3).

Vitamin C (ascorbic acid) is also an effective antioxidant and its antioxidant properties depend on two different mechanisms that inhibit lipid peroxidation. Firstly, vitamin $\mathrm{C}$ restores the oxidized form of vitamin $\mathrm{E}$ and maintains the necessary concentration of this antioxidant in the cell membranes. Secondly, being a watersoluble and strong reducing agent, vitamin $\mathrm{C}$ interacts with watersoluble active forms of oxygen $\left(\mathrm{O}_{2}^{-}, \mathrm{H}_{2} \mathrm{O}_{2}, \mathrm{OH}^{*}\right)$ and inactivates them.

The results of the present study have shown that the leaves of cabbage kale are a rich source of vitamin C. The investigation of Brassica oleracea var. Sabellica composition at different stages of development indicated that the content of vitamin $\mathrm{C}$ had increased during ontogenesis (EryilmazAcikgoz, 2011). In the present study also the concentration of ascorbate has risen with the increase of plants age (Fig. 4). Streb et al., (1999) reported that the content of ascorbic acid and $\alpha$-tocopherol was higher at low temperatures in cold-resistant varieties of plants. Similarly, Conklin et al. (1996) suggested that although ascorbate is present in leaves under ordinary conditions, its accumulation is dependent on the stage of development and environmental conditions, which could affect the rate of reactive oxygen species of formation. On the other hand, a higher level of ascorbate in cabbage kale leaves after 145 days of planting at $-60 \mathrm{C}$ temperature indicates that oxidative stress can contribute to the biosynthesis and accumulation of ascorbate in kale leaves. This is a protective reaction of plants.

However, the results of the present study suggested that all growth regulators except brassinolide reduced the amount of ascorbate compound (Figure 4). Similarly, Sun et al. (2012) reported that the treatment of Chinese cabbage (Brassica alboglabra Bailey) with plant hormones (methyl jasmonate, ethrel, and 1methylcyclopropene) had a negligible effect on the content of vitamin $\mathrm{C}$ after 6 days of application, except salicylic acid which reduced by almost one third after the treatment.

B-carotene, the precursor of vitamin A, also has an antioxidant effect and inhibits lipid peroxidation. It is also known that carotenoids remove free radicals from the system, interact with them, resulting in the formation of harmless products, or disrupt the chain reactions, associated with free radicals. The conjugated double-bond system in the carotenoid molecule is primarily responsible for the ability of b-carotene to "quench" singlet oxygen. Besides, carotenoids can interact with organic radicals of fatty acids, acting as the "traps" for radicals and as a result, the oxidation chain breaks (Britton, 1969).

Many researchers have demonstrated that the largest number of carotenoids was detected in the middle of ontogenesis, and later on, it gradually decreased. The results of the current study also suggested that the level of carotenoids has declined from 85 to 145 days after planting (Figure 5). Similarly, Ovcharov, (1969) conducted a study on Medicago falcate, M. sativa, and Pisum sativum and reported that the highest content of carotenoids was reported at the early stage of growth, after this it gradually dropped and during the fruiting level of carotenoids decreased many times.

Further, a reduction in the temperature also contributes to the reduction of carotenoid content. Results of the current study are in agreement with the findings of Kopsell et al. (2005), those who reported that the concentration of lutein and beta-carotene increased linearly with the rise of air temperature (from 10 to $25^{\circ} \mathrm{C}$ ). The content of carotenoids has increased under the influence of all applied phytohormones to varying degrees and among the tested phytohormones, gibberellic acid had the highest effect (Figure 5).

Exogenous treatment with GA3 can stimulate the formation of carotenoid precursor - geranylgeranyl diphosphate, thereby contributing to an increase in the number of carotenoids in cabbage plants. These results are confirmed by the findings of Sardoei \& Shahdadneghad (2014), those who sprayed gibberellic acid (50 mg $\mathrm{L}^{-1}$ ) on Marigold (Calendula officinalis L.) and found that the content of carotenoids has increased with increases GA concentration. 
Proline is also one of the most important multifunctional stress metabolites of plants. It is believed that in addition to the old-established osmoprotective function, proline also performed various other functions such as chaperone, antioxidant, and signal-regulatory. Many studies have reported a significant reduction in the product of lipid peroxidation (LPO) of malondialdehyde in plant tissues, which is influenced by the presence of proline under stressful conditions. It is assumed, that proline may also have osmoprotective value under the frost hardening conditions of plants (Kolupaev et al., 2014).

The result of the current study suggested that the level of proline was slightly higher under the negative temperatures $\left(-6^{0} \mathrm{C}\right)$ conditions as compared to the positive temperatures. Growth regulators have increased proline content under different growing conditions and among the tested growth hormones, Novosil and gibberellic acid have the highest effect (Figure 6). Similarly, Shahram (2015) reported that spraying of gibberellin increased the amount of proline in maize hybrids under drought conditions, but didn't affect its content under normal growing conditions (without stress). This is consistent with our results, since gibberellin did not have any impact on the amount of proline at positive temperatures, and increased its content in cabbage kale leaves only at low temperatures.

Peroxidase, catalase, ascorbate peroxidase, superoxide dismutase, glutathione peroxidase are the enzymes that protect cells from the

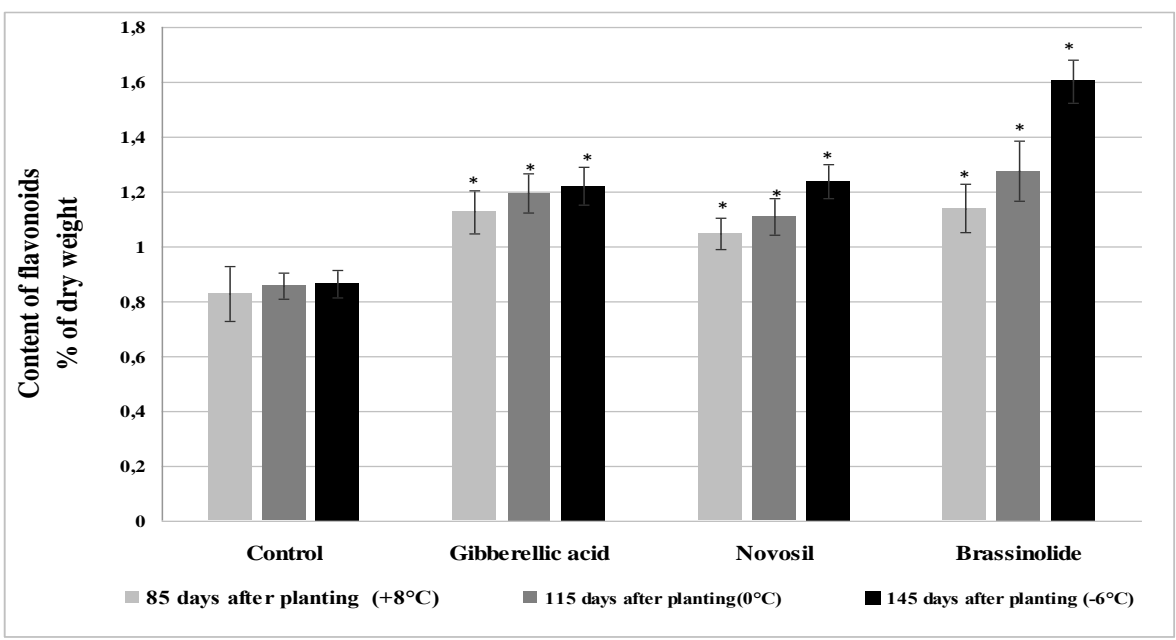

Figure 3 Effect of growth regulators on the content of flavonoids in B. oleracea var. Sabellica

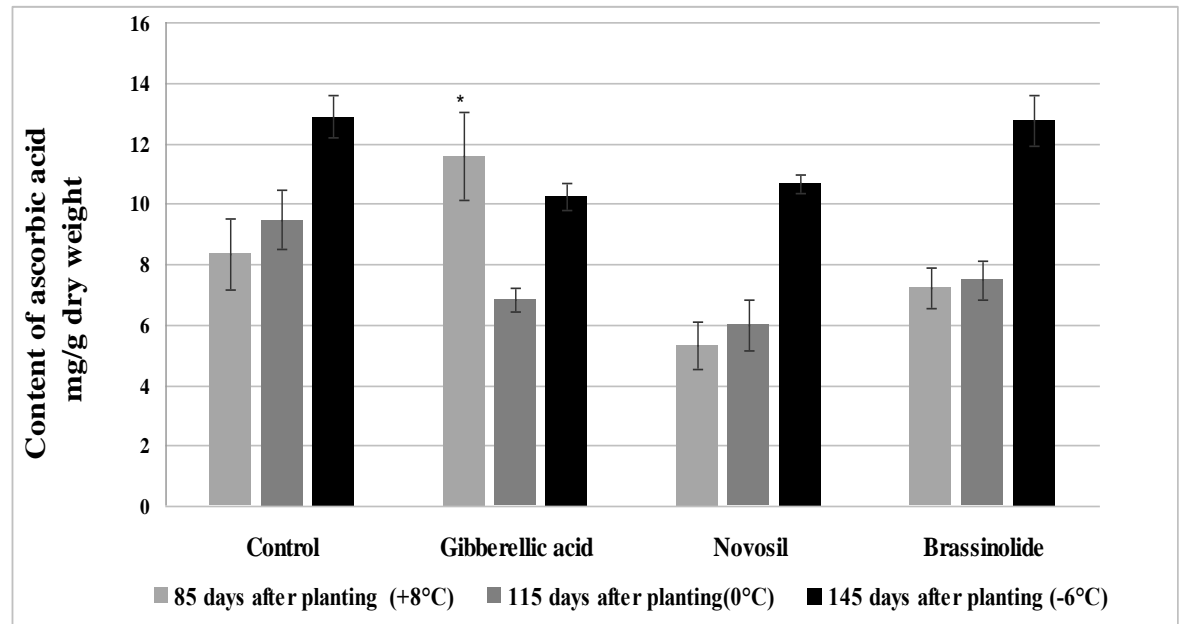

Figure 4 Effect of growth regulators on the content of ascorbic acid in B. oleracea var. Sabellica

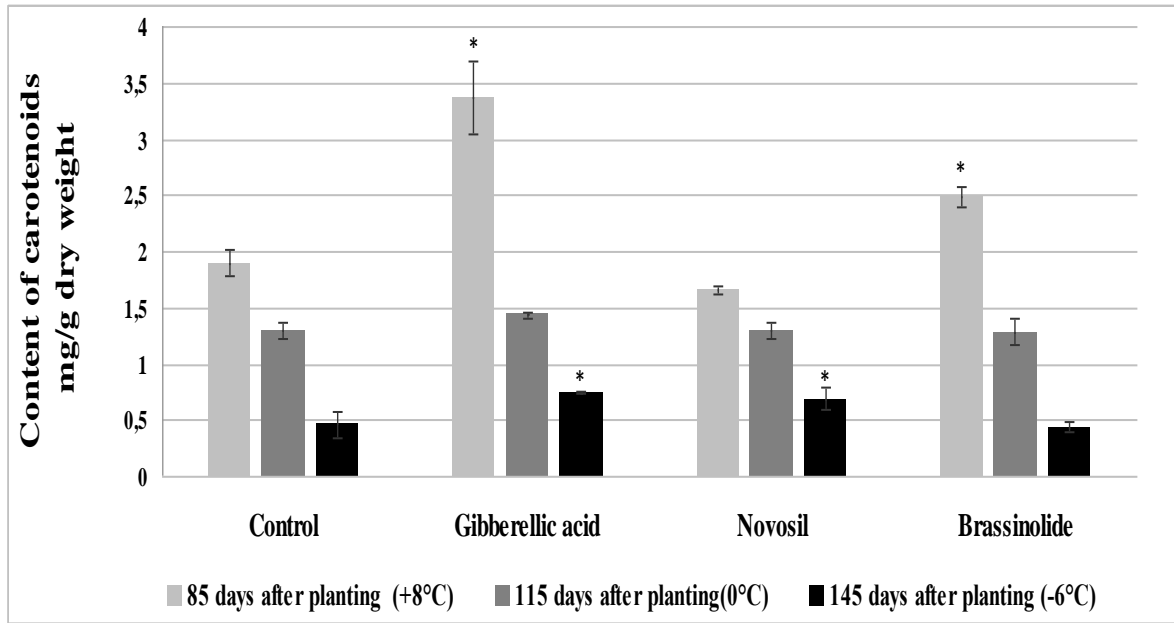

Figure 5 Effect of growth regulators on the content of carotenoids in B. oleracea var. Sabellica 
action of reactive oxygen species. Metabolisms produced by catalase, peroxidase and ascorbate peroxidase are protective and help in the adaptation of organism under stress conditions. Also, catalase and peroxidase play an important role in the processes of cell growth and differentiation (Molassiotis et al., 2004), since these are of paramount importance in the formation of lignin and maintaining of cell wall rigidity (Whetten et al., 1998).

The study of these enzymes in the current study suggested that the activities of these enzymes had increased during the ontogenetic development and are under the influence of growth regulators. This action of gibberellic acid and Novosil was especially stronglypronounced under the conditions of freezing temperatures (Figure 7-9).

The ability of gibberellic acid to influence the level of peroxidase in seeds has long been known (Harmey \& Murray, 1968). The plant growth regulator, diterpeneglycoside stevioside, also causes a decline in MDA formation in wheat seedlings and increases the activities of antioxidant enzymes peroxidase and ascorbate peroxidase (Timofeeva et al., 2015).

\section{Conclusion}

The result of the current study concluded that various growth regulators have varying degrees of antioxidant activities on cabbage kale increased. The antioxidant properties of cabbage kale improved after the first frost exposure which suggested the late harvest of cabbage kale. Among the studied growth regulators, terpenoidal compounds of Novosil and gibberellic acid improved the

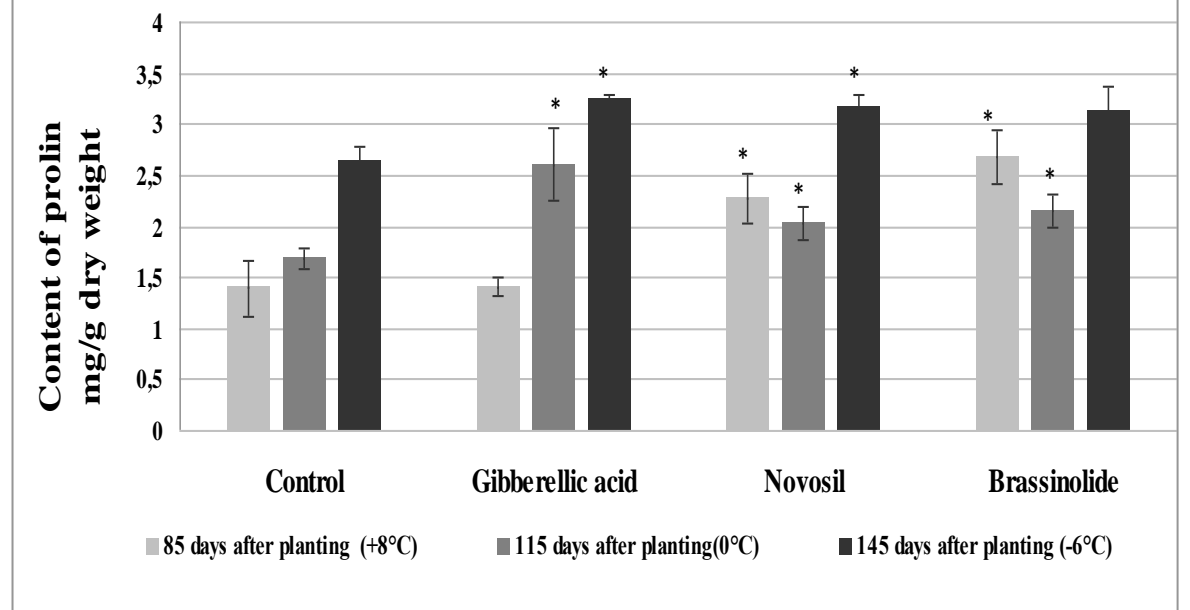

Figure 6 Effect of growth regulators on the content of proline in B. oleracea var. Sabellica

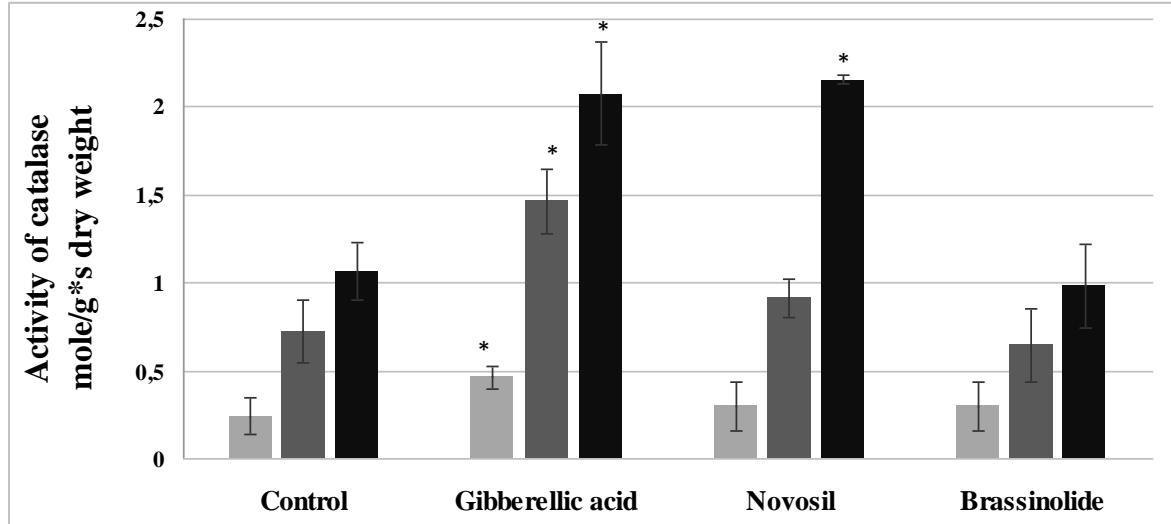

85 day after planting $\left(+8^{\circ} \mathrm{C}\right) \square 115$ day after planting $\left(0^{\circ} \mathrm{C}\right) \square 145$ day after planting $\left(-6^{\circ} \mathrm{C}\right)$

Figure 7 Effect of growth regulators on the activity of catalase in B. oleracea var. Sabellica

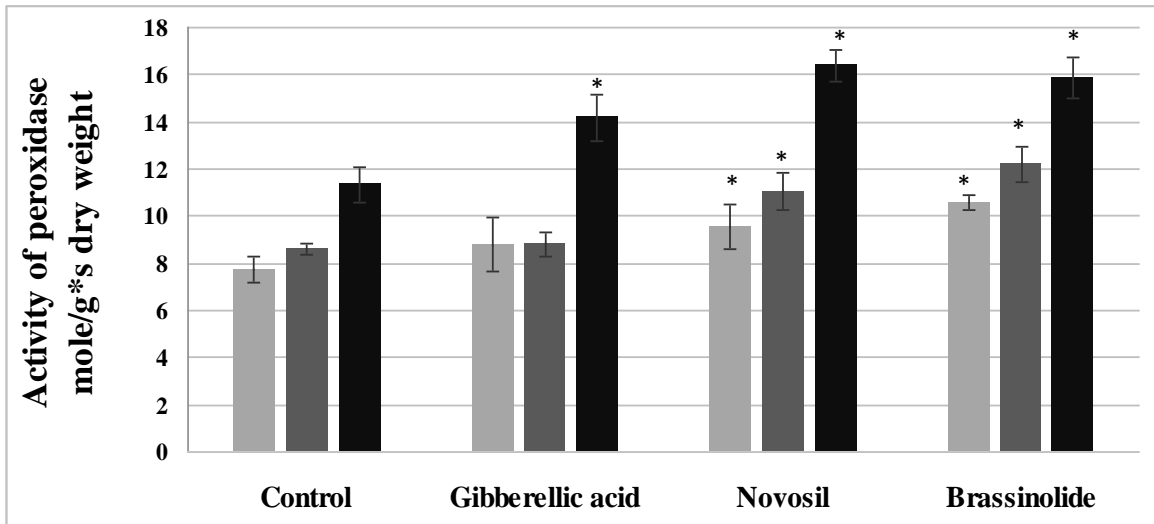

$\square 5$ day after planting $\left(+8^{\circ} \mathrm{C}\right) \square 115$ day after planting $\left(0^{\circ} \mathrm{C}\right) \square 145$ day after planting $\left(-6^{\circ} \mathrm{C}\right)$

Figure 8 Effect of growth regulators on the activity of peroxidase in B. oleracea var. Sabellica 


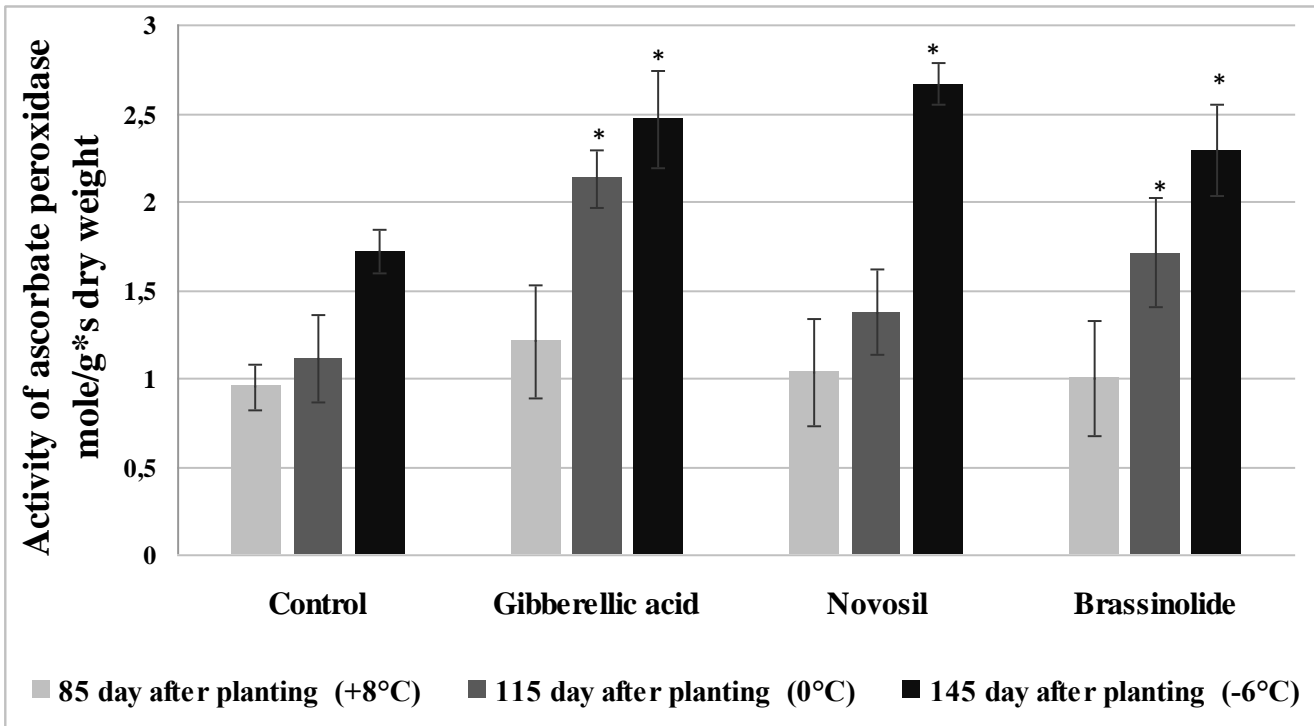

Figure 9 Effect of growth regulators on the activity of ascorbate peroxidase in B. oleracea var. Sabellica

antioxidant activity in cabbage kale leaves at the late stages of development, activating antioxidant enzymatic systems and content of carotenoids and proline which also help in this. The steroidal compound of brassinolide raises the content of phenolic and flavonoids compounds. The results obtained from the study indicated that the application of growth hormones not only increases the synthesis of protective compounds to develop the resistance of cabbage kale plants against adverse environmental conditions but also improve the biomedical properties of this. The protective effect of growth regulators against lipid peroxidation and their antioxidant activity has enhanced under the freezing temperatures $\left(-6^{0} \mathrm{C}\right)$.

\section{Acknowledgements}

The work is performed according to the Russian Government Program of Competitive Growth of Kazan Federal University.

\section{Conflict of Interest}

Authors would hereby like to declare that there is no conflict of interests that could possibly arise.

\section{References}

Bates LS, Waldren RP, Teare ID (1973) Rapid determination of free proline for water-stress studies. Plant and Soil 39: 205-207.

Britton G (1969) Structure and properties of carotenoids in relation to function. FASEB 9:1551-1558.

Conklin PL, Williams EH, Last RL (1996) Environmental stress sensitivity of an ascorbic acid-deficient Arabidopsis mutant Proceedings of National Academy of Science 93:9970-9974.
Edreva A (2005) The importance of non-photosynthetic pigments and cinnamic acid derivatives photoprotection. Agriculture, Ecosystems \& Environment 106: 135-146.

Efimova MV, Vankova R, Kusnetsov VV, Litvinovskaya RP, Zlobin IE, Dobrev P, Vedenicheva NP, Savchuk AL, Karnachuk RA, Kudryakova NV, Kuznetsov VV (2017) Effects of 24-epibrassinolide and green light on plastid gene transcription and cytokinin content of barley leaves. Steroids 120: $32-40$.

EryilmazAcikgoz F (2011) Mineral, Vitamin C and crude protein contents in Kale (Brassica Oleraceae Var. Acephala) at different harvesting stages. African Journal of Biotechnology 10:1717017174.

Falcone Ferreyra ML, Rius SP, Casati P (2012) Flavonoids: biosynthesis, biological functions and biotechnological applications. Frontiers in Plant Science 3:1-15.

Fiol M, Adermann S, Neugart S, Rohn S, Mügge C, Schreiner M (2012) Highly glycosylated and acylatedflavonols isolated from Kale (Brassica Oleracea Var. Sabellica) - Structure Antioxidant Activity Relationship. Food Research International $47: 80-89$.

Harmey MA, Murray AM (1968) The effect of gibberellic acid on peroxidase levels in barley. Planta (Berl) 83: 387-389.

KolupaevYu E, Wainer AA, Yastreb TO (2014)Proline: physiological functions and regulation of the content in plants under stressful conditions. The Bulletin of Kharkiv National Agrarian University Series Biology 2(32): 6-22. 
Kopsell DA, Lefsrud MG, Kopsell DE, Curran-Celentano J (2005) Air temperature affects biomass and carotenoid pigment accumulation in kale and spinach grown in a controlled environment. HortScience 40(7): 2026-2030.

Kumar GNM, Knowles NR (1993) Changes in lipid peroxidation and lipolitic and freeradical scavenging enzyme activities during aging and sprouting of potato (Solanumtuberosum) seed-tubers. Plant Physiology 102: 115-124.

Levitt J (1980) Responses of plants to environmental stresses. New York: Academic Press, Pp. 365.

Mittler R (2002) Oxidative Stress, Antioxidants and Stress Tolerance. Trend in Plant Science 7:405-410.

Moheb A, Ibrahim RK, Roy R, Andsarhan F (2011) Changes in wheat leaf phenolome in response to cold acclimation. Phytochemistry 72:2294-2307.

Molassiotis AN, Dimassi K, Diamantidis G, Therios I (2004) Changes in peroxidases and catalase activity during in vitro rooting. Biologia Plantarum 48: 1-5.

Ovcharov KE (1969) Plant Vitamins, Kolos,. Pp.326.

Pandjaitan N, Howard LR, Morelock T, Gil M (2005) Antioxidant capacity and phenolic content of spinach as affected by genetics and maturation. Food Chemistry 3: 8618-8623.

Prassad TK (1996) Mechanisms of chilling-induced oxidative stress injury and tolerance developing maize seedlings: changes in antioxidant system, in oxidation of proteins and lipids, and protease activities. Plant Journal 10: 1017-1026.

Sardoei AS, Shahdadneghad M (2014) Effects of foliar application of gibberellic acid on chlorophyll and carotenoids of Marigold (Calendula Officinalis L.). International Journal of Advanced Biological and Biomedical Research 2(6): 18871893.

Schmidt SA, Zietz MB, Schreiner MA, Rohn SB, Kroh LW, Krumbein AB (2010) Genotypic and climatic influences on the concentration and composition of flavonoids in Kale (Brassica Oleracea Var. Sabellica). Food Chemistry 119:1293-1299.

Shahram M (2015) Investigating the effect of gibberellic acid and kinetin hormones on proline, protein and carbohydrates of leaf soluble in Maize hybrids under drought stress.Cumhuriyet
University. Faculty of Science.Cumhuriyet Science Journal 36(3): 604-613.

Sibgatullina GV, Khaertdinova LR, Gumerova EA, Akulov AN, KostyukovaYuA, Nikonorova NA, Rumyantseva NI (2011) The methods for determination of the redox status of cultivated plant cells: teaching manual: Kazan (Volga) Federal University, Pp. 61.

Sikora E, Cieslik E, Leszczynska T, Filipiak-Florkiewicz A, Pisulewski PM (2008)The antioxidant activity of selected cruciferous vegetables subjected to aqua thermal processing. Food Chemistry 107: 55-59.

Sokolovsky VV, Lebedeva LV, Lielup TB (1974)On the method for the separate determination of ascorbic, dehydroascorbic and diketogulonic acids in biological tissues. Laboratory Science 3: $57-$ 63.

Streb P, Shang W, Feierabend J (1999) Resistance of coldhardened winter rye leaves (SecaleCereale L.) to photo-oxidative stress. Plant Cell and Environment 22:1211- 1223

Sun B, Yan H, Zhang F, Wang Q (2012) Effects of plant hormones on main health-promoting compounds and antioxidant capacity of Chinese kale. Food Research International 48(2): 359-366.

Timofeeva OA, NevmerzhitskayaYY, Mikhailov AL, Shaimullina GK (2015) Stevioside prevents the development of oxidative stress in wheat seedlings. Reports of the Academy of Sciences 465(6): 1-3.

Velioglu YS, Mazza G, Gao L, Oomah BD (1999) Antioxidant activity and total phenolics in selected fruits, vegetables, and grain products. Agricultural and Food Chemistry 46: 4113-4117.

Vorobyev VN, NevmerzhitskayaYY, Khusnetdinova LZ, Yakushenkova TP (2013) Workshop on plant physiology: teaching manual: Kazan University, Pp. 80.

Whetten RW, Mackay JJ, Sederoff RR (1998) Recent advances in understanding lignin biosynthesis. Annual Review of Plant Physiology and Plant Molecular Biology 49. - Pp. 585-609.

Zhishen J, Mengcheng T, Jianming W (1999) The determination of flavonoid contents in mulberry and their scavenging effects on superoxide radicals. Food Chemistry 64: 555-559.

Zhou K, YuL (2006) Total phenolic contents and antioxidant properties of commonly consumed vegetables grown in Colorad. LWT - Food Science and Technology 39: 1155-1162. 